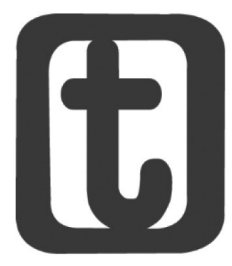

\title{
HOMOSSEXUALIDADE: SEXUALIDADE NO ENVELHECIMENTO
}

\author{
HOMOSEXUALITY: SEXUALITY IN AGING
}

\section{Alessandra Rocha Arrais ${ }^{1}$ Andreia Aparecida Lima ${ }^{2}$ Kelly Cristina Santiago 3}

\section{RESUMO}

A homossexualidade não é um assunto de fácil compreensão dentro da nossa sociedade e no âmbito familiar. Porém, quando se refere à homossexualidade na velhice, torna-se mais complexa. A hipótese levantada é de que a homossexualidade pode ser vivida e assumida na velhice, inicialmente pelo fato de as pessoas envelhecidas já terem cumprido seus papéis sociais referentes à idade adulta e passarem a adaptá-los a uma nova fase. Ainda, a realidade social, quanto ao conhecimento de relações homossexuais em diferentes faixas etárias, é um assunto bastante relevante. Consequentemente, o objetivo deste estudo é entender a homossexualidade e a velhice em conjunto com os medos e conflitos que essas duas vertentes trazem para o ser que envelhece. Trata-se de um estudo de caso de um adulto de 40 anos do gênero masculino, assumidamente homossexual, que relatou através de uma entrevista seus temores quanto ao processo de envelhecimento, bem como a relação

1 Possui graduação (1992), mestrado (1997) e doutorado (2005) em Psicologia pela Universidade de Brasília. Psicóloga da Secretaria de Estado de Saúde do Distrito Federal e profissional liberal em consultório de psicologia clínica. E-mail: alearrais@gmail.com.

2 Acadêmica do curso de Fisioterapia das Faculdades Integradas da União Educacional do Planalto Central - FACIPLAC. E-mail: andreialimafisio@gmail.com.

3 Mestre em Gerontologia UCB-DF, especialista em Ortopedia e Traumatologia UCB-RJ, graduada em Fisioterapia pelas Faculdades Integradas da União Educacional do Planalto Central - FACIPLAC. Professora da graduação da FACIPLAC e da FACESA. E-mail: criskel@gmail.com. 


\section{temporalis}

entre homossexualidade e velhice. $O$ delineamento desta pesquisa é um estudo de caso, qualitativo, retrospectivo. Os dados foram analisados de acordo com a análise de conteúdo, que tem como pilares a fase da descrição ou preparação do material, a inferência ou dedução e a interpretação. Os principais resultados obtidos foram a associação da homossexualidade com a vaidade e a velhice, assim como os aspectos financeiros e a maturidade adquiridos com a idade como elementos facilitadores do reconhecimento e expressividade da homossexualidade. Sendo assim, conclui-se que idosos homossexuais existem e que eles enfrentam as mesmas dificuldades, conflitos e medos que seus pares etários heterossexuais.

Palavras-chave: Homossexualidade. Sexualidade. Velhice.

\section{ABSTRACT}

Homosexuality is not a subject easily understandable within our society and within the family. However, when treated in old age it becomes more complex. Our hypothesis is that homosexuality can be lived and accepted in old age, initially because of the aged people have already fulfilled their social roles related to adulthood and begin to adapt these to a new phase. Still, the social reality in terms of knowledge of homosexual relationships in different age groups is a very relevant subject. Consequently, the aim of this study is to understand homosexuality and old age together with the fears and conflicts that these two aspects bring to aging individuals. This is a case study of a 40 years old adult male, openly gay, that reported through an interview his fears about aging process, as well as the relationship between homosexuality and old age. The design of this research is a case study, qualitative, retrospective. Data were analyzed according to content analysis, which is founded on the stage of description or preparation of the material, the inference or deduction and the interpretation. The main results were the association of homosexuality with vanity and old age, as well as the financial aspects and the maturity acquired with age as enablers of recognition and expression of homosexuality. Thus, we conclude that elderly homosexuals exist and face the same difficulties, conflicts and fears that their age heterosexual peers do.

Keywords: Homosexuality. Sexuality. Aging.

Submetido em 03/04/2014

Aceito em 17/09/2014 


\section{INTRODUÇÃO}

A velhice é, de modo geral, uma fase bastante temerosa e assustadora. Filósofos, religiosos, pensadores, homens e mulheres de todos os tempos salientam a certeza da finitude no processo de envelhecimento. A associação que se faz entre a velhice e a morte nada tem de atual, ela se realiza diferentemente em épocas e culturas distintas (MARAVILHA, 2010).

O processo de envelhecimento populacional deu-se através da diminuição nas taxas de fecundidade e de mortalidade que levaram a mudanças na estrutura da população por idade e sexo devido a uma maior esperança de vida. No caso brasileiro, a partir do final da década de 1960, observaram-se um rápido e generalizado declínio da fecundidade e, consequentemente, um célere processo de envelhecimento da população (CARVALHO; GARCIA, 2003).

Diante do impacto que representa o processo de envelhecimento, evidencia-se a necessidade de mais estudos sobre o ser que envelhece inserido nas diferenças que marcam sua permanência e identidade grupal na sociedade, bem como de uma discussão a respeito do envelhecimento enquanto fenômeno psicossocial, pois o indivíduo passa grande parte da sua vida vivendo coletivamente, com seus familiares, no seu trabalho, com seus amigos e, quando envelhece, sofre com a discriminação da sociedade no setor produtivo, da família no convívio social, tendendo a se isolar, a se anular, sentindo-se incapaz perante a sociedade e a família (CAMARANO, 2006, p. 88).

Diante desse cenário, inúmeros temas merecem atenção frente ao envelhecimento da população e aos diferentes aspectos que podem ser abordados. Dentre eles, destaca-se a sexualidade na velhice.

A sexualidade no envelhecimento constitui um assunto contaminado por preconceitos sociais, culturais, familiares e até mesmo pessoais. As crenças equivocadas acerca da sexualidade dos idosos reforçam os argumentos de que, com o envelhecimento, a atividade sexual perde seu objetivo de procriação e, consequentemente, sua justificativa social (MARAVILHA, 2010, p. 30). 


\section{temporalis}

A sexualidade não representa apenas o ato sexual. Permeia as relações afetivas através das carícias, dos olhares de atenção dispensados carinhosamente ao outro, de um cinema, uma dança, uma boa conversa. Ela pode transformar-se em outros modos de expressão. Assim, resgatar o direito a uma vida sexual da pessoa idosa pode ser realizado de várias formas.

Nessa perspectiva, a sexualidade pode ser vivida intensamente por todos e principalmente pelo ser que envelhece, sendo que $o$ ato sexual pode ser apenas um complemento.

Dentre os temas voltados para a sexualidade em idosos, ressalta-se um ainda pouco explorado: a homossexualidade na velhice.

O objetivo geral deste estudo foi entender a homossexualidade e a velhice em conjunto com os medos e conflitos que essas duas vertentes trazem para o ser que envelhece.

A justificativa baseia-se em uma investigação de um grupo de idosos homossexuais como contribuição para um envelhecimento saudável e com qualidade, ao buscar o estímulo à sociabilidade e a inserção na família, bem como remetendo à questão do apoio social e sua repercussão positiva na saúde.

A homossexualidade na terceira idade não é um assunto comum, de fácil compreensão, tampouco de grande aceitação na sociedade e no âmbito familiar. Nossa hipótese é a de que a homossexualidade talvez possa ser vivida e assumida com uma maior facilidade na velhice, inicialmente pelo fato de as pessoas envelhecidas já terem cumprido seus papéis sociais referentes à idade adulta e passarem a adaptar seus papéis sociais a uma nova fase.

O corpo envelhecido é quase sempre visto como desprovido de sexualidade e desejo. A sociedade muitas vezes classifica essa etapa da vida como um período de assexualidade e em alguns momentos de androginia, por tratar-se de uma fase em que o idoso deveria assumir unicamente o papel de avó ou avô, cuidando de seus netos, vendo televisão e fazendo tricô, esperando a morte chegar e encarando a sexualidade do idoso como um ato pecaminoso e maléfico (MARAVILHA, 2010, p. 24). 
Historicamente, construiu-se o mito da sexualidade do idoso tendo como ponto de partida o adulto viril. Assim, toda mudança decorrente do processo de envelhecimento do indivíduo em sua trajetória existencial traria a diminuição e até mesmo o desaparecimento do desejo, e aqueles que buscassem se manifestar sobre a sua sexualidade sofreriam a decepção das dificuldades impostas pela idade (RISMAN, 2005).

Dessa forma, o ato sexual foi inserido em uma escala temporal em que não pode ser instituído precocemente, tampouco tardiamente. Em outras palavras, crianças e idosos são naturalmente assexuados, pois a atividade sexual foi naturalizada por sua funcionalidade para procriação (OLIVEIRA; OLIVEIRA; IGUMA, 2007).

As periodizações da vida humana, historicamente, demarcaram a expressão da sexualidade, mostrando-se a serviço do controle social e da hierarquização dos papéis nas sociedades contemporâneas, destinando ao idoso uma política de retidão, alicerçada no abandono da sexualidade e das funções estranhas ao ambiente da casa e da família, sobretudo no caso da mulher idosa (MARAVILHA, 2010).

A construção do conhecimento sobre envelhecimento e sexualidade está pautada na norma heterossexista da sociedade, denunciando o desinteresse em trazer à tona a possibilidade de sexualidades distintas ao longo da vida e a homossexualidade no percurso do envelhecimento (MARAVILHA, 2010).

Pinho (2008) descreve a homossexualidade como produto das inúmeras transformações socioculturais no mundo ocidental, ancoradas no conhecimento médico, científico e espiritual que, ao longo da história das sociedades tradicionais e contemporâneas, apreenderam e reformularam as concepções da sexualidade bem como suas variações, de maneira que a homossexualidade esteve sempre em trânsito entre uma prática aceita e uma condenável.

O conceito homossexual, segundo Nunam (2003, p. 56), é tão histórica e socialmente construído quanto qualquer outro termo. A criação de uma palavra corresponde ao desenvolvimento de uma essência, doença psíquica ou um mal social, que 


\section{temporalis}

depende do momento e contexto histórico do qual ela emerge. $\mathrm{O}$ autor afirma ainda que tanto homossexualidade quanto heterossexualidade são identidades socioculturais histórica e socialmente construídas, as quais norteiam maneiras de viver, sentir, pensar, e não uma lei universal da diferença de sexos.

Esta pesquisa trata-se de um estudo de caso, qualitativo, retrospectivo. A esse respeito, Serapioni (2000, p. 188) aponta que "o estudo qualitativo trabalha com valores, crenças, representações, hábitos, atitudes e opiniões. Focalizam as particularidades e as especificidades dos grupos sociais estudados, devem ser utilizados quando o objeto de estudo não é bem conhecido". Esse é o caso da temática homossexualidade em idosos, sobre a qual não há muitos estudos.

O estudo qualitativo ainda possui a capacidade de fazer emergir aspectos novos, de ir ao fundo do significado e de estar na perspectiva do sujeito. Assim, os métodos qualitativos são aptos para descobrir novos anexos e explicar significados (SERAPIONI, 2000).

É retrospectivo porque identifica uma amostra no passado, coleta dados sobre as variáveis preditoras, bem como sobre as variáveis de desfecho, medidas no passado ou no presente (HULLEY et al. 2008).

A investigação foi realizada em Brasília, onde a pesquisadora agendou um encontro para a aplicação da entrevista de acordo com a disponibilidade do participante, o qual tem 40 anos, do gênero masculino, com nível superior de escolaridade, sendo autorreconhecido, isto é, assumida e declaradamente homossexual.

A pesquisa foi aprovada pelo comitê de ética da Universidade Católica de Brasília, sob o número 164/2011, e um dos critérios exigidos aos participantes foi que eles somente poderiam compor o estudo mediante assinatura do termo de consentimento livre e esclarecido se aceitassem ser submetidos ao instrumento de coleta de dados escolhido e tivessem disponibilidade de tempo para encontrar com o pesquisador. 
Para se atingir os objetivos da pesquisa, o instrumento de coleta de dados escolhido foi a entrevista semiestruturada.

Devemos entender por entrevista semiestruturada aquela em que o investigador oferece todas as perspectivas possíveis para que o sujeito investigado alcance a liberdade e a espontaneidade necessárias, enriquecendo a investigação (TRIVINOS 1994 apud SANTOS, 2002).

O termo semiestruturado aplicado à entrevista compreende o significado de o entrevistador definir antecipadamente a estrutura geral da entrevista, estabelecendo que tópicos serão abordados e quais as questões principais que serão perguntadas. Deve ficar claro para o entrevistado que certos detalhes são trabalhados durante a entrevista a partir da interação entre entrevistador e entrevistado (GALVÃO, 2001).

Os dados são analisados de acordo com a análise de conteúdo de Bardin (2011), que tem como pilares a fase da descrição ou preparação do material, a inferência ou dedução e a interpretação.

Dessa forma, os principais pontos da pré-análise são: a leitura flutuante (primeiras leituras de contato com os textos), a escolha dos documentos (no caso, os relatos transcritos), a formulação das hipóteses e objetivos (relacionados com a pesquisa), a referenciação dos índices e elaboração dos indicadores (a frequência de aparecimento) e a preparação do material (BARDIN, 2011).

\section{RESULTADOS E DISCUSSÕES}

Na apresentação do discurso do entrevistado no corpo do texto, utilizaremos um nome fictício, Gabriel, para preservar a identidade do participante.

Gabriel é um adulto de 40 anos, homossexual, que se reconheceu na adolescência e passou por toda essa fase e a "adultez" convivendo com os medos e conflitos gerados pelo seu desejo homossexual. Buscou informação, estuda, trabalha, está inserido social e familiarmente após se assumir, com 37 anos.

Sua aceitação aconteceu gradativamente, sempre foi apaixonado por um primo e achava aquela situação muito estranha, 


\section{temporalis}

porém nunca se relacionou intimamente com ele. Quando foi para a oitava série, com 13 e 14 anos, começou a sentir a mesma coisa por um colega de sala de aula. Então nas aulas de educação física ele reparava que fazia de tudo para sair na mesma equipe desse colega, criava situações para sempre estar perto dele. Daí descobriu que aquilo não era normal e ficava se questionando, nesse momento realmente começou a ter a consciência de que tinha algo de diferente.

Aos 17 anos, quando entrou para a faculdade, começou a ler sobre o assunto e teve a primeira relação sexual, a respeito da qual relatou que parecia "sujo", que havia cometido um crime. Então, a partir desse momento, iniciou-se um conflito entre o desejo e a aceitação, mas, ao mesmo tempo, nessa ocasião passou a pensar, a questionar; assim, quando Gabriel ia para a biblioteca fazer trabalhos da faculdade, começava a pesquisar em livros sobre a homossexualidade, e, desde essa época, ele se aceitou como homossexual e decidiu trabalhar essa questão dentro dele, porém o que mais o preocupava era o âmbito familiar.

Gabriel encontra-se inserido em uma família unida, porém tradicional, decorrente de uma sociedade conservadora, em que a família é constituída por um homem e uma mulher, estando unidos por matrimônio, em que o resultado dessa união são os filhos. Por esse motivo, ele temia as consequências que a sua revelação acarretaria no seio familiar.

Ele teve um relacionamento de cinco anos que gerou várias desconfianças por parte de seus familiares, até que em um dia sua mãe o questionou. Então, aos 38 anos, a sua homossexualidade foi reconhecida por seus familiares.

Durante o período entre a sua formação acadêmica e a inclusão no mercado de trabalho sofreu preconceitos, dificuldade de inclusão social, porém buscou sua formação e ascensão profissional, não permitindo que a sociedade o "engolisse" e nunca deixou de se autodeclarar homossexual.

[...] tive a primeira relação, aconteceu, e claro que quando acontece a primeira relação a gente se sente muito é... não é sujo a palavra, mas a gente se sente, parece que a gente cometeu um crime, 
entendeu? Eu cheguei na minha casa e olhei para as minhas tias que eu estava morando com elas, e parecia que estava escrito na minha testa, e estava morrendo de medo de alguém perguntar o que estava acontecendo. Por que você está estranho? O que aconteceu? E então é um conflito entre o desejo e a aceitação, mas ao mesmo tempo foi a partir daí que eu comecei a pensar, aí eu fui e comecei a questionar...

É evidente na fala de Gabriel o sentimento de angústia, medo, ao se deparar com inúmeras variáveis que permeiam a sexualidade, o desejo homossexual, relacionado primeiramente com seu autorreconhecimento e, posteriormente, com a aceitação familiar e social.

Isso se justifica através da constatação realizada por Maravilha (2010), que descreve que no Brasil a expressão da homossexualidade tem conferido àqueles que assumem uma orientação sexual "desviante da norma" um caminho árduo na luta por seus direitos enquanto cidadãos, desde o direito de ir e vir até a luta pelo direito de amar aquele que lhe é igual. A homossexualidade sempre foi encarada como uma face desafiadora aos padrões da "normalidade" e aceitabilidade social, intrigando por sua elasticidade dentro da sexualidade humana, bem como produzindo atração e repulsa nas esferas da sociedade.

Observa-se que o processo de autorreconhecimento de Gabriel ocorreu na fase jovem, porém o reconhecimento familiar e social se deu na fase adulta, o que nos faz refletir acerca do processo de envelhecimento associado ao reconhecimento do desejo homossexual. Quando relacionamos essas duas vertentes, podemos perceber que a maturidade advinda da passagem entre os ciclos vitais, ligada a uma boa colocação social e financeira, talvez contribua para a expressividade da homossexualidade.

[...] o adolescente de hoje, eu acho que ele é o contrário, os pais aceitam um pouco mais pelo, ele vai, ah, sou mesmo e "foda-se" o universo, mas ao mesmo tempo eu não concordo, pois eles assumem de uma forma totalmente irresponsável, taí as pesquisas até em relação a doenças o tanto que aumentou, 


\section{temporalis}

então tudo aconteceu muito debaixo do pano, era como se eu tivesse uma vida dupla...

[...] eu acho que não tem um período certo, ele pode ser a qualquer momento, então se as pessoas às vezes se assumem mais velhas, o que contribuiu para isso? Porque ela já se sente mais confortável, em termos profissionais, em termos financeiros, independência...

Analisando a colocação de Gabriel quanto ao processo de envelhecimento e ao reconhecimento da homossexualidade, associamos a visão da sociedade no que diz respeito aos aspectos da sexualidade e do envelhecimento.

No aspecto social e familiar, lidar com a sexualidade na velhice já é bastante conflitante, sobretudo quando a homossexualidade torna-se evidente e exteriorizada. Destacam-se as perdas de papéis ocupacionais significativos, muitas vezes com restrição à participação na sociedade, atingindo incisivamente os idosos, que interiorizam conceitos negativos, estabelecendo uma condição conflitante, dificultando a autoaceitação e proporcionando uma baixa autoestima, aliada a uma limitada qualidade de vida.

Entre os homossexuais, a relação envelhecimento-sexualidade está embasada em uma sensação de perda que perpassa o valor atribuído à estética e ao vigor da juventude de forma bastante explícita. Não ser mais dotado de atrativos físicos evidentes e não responder como outrora aos estímulos sexuais é sentido com muita consternação. Os homossexuais repulsam a imagem que seus corpos trazem como simbologia da decrepitude, na medida em que representa para eles o fim de uma fase glamourosa, da qual todos querem fugir (MARAVILHA, 2010).

A vaidade e o medo de envelhecer sempre nos acompanharam por todos os ciclos da vida e, para o homossexual, essa questão é bem relevante. Nesse sentido, Gabriel expressa seu medo de envelhecer, quando começa a relacionar a beleza com o envelhecimento.

[...] "na homossexualidade, as pessoas dão muito valor a aparência e ao status, então se você é um idoso que tem uma estabilidade financeira alta, você não vai ter tantos problemas, entre aspas, 
porque na realidade você vai estar pagando para ter alguém do seu lado"...

[...] "a homossexualidade e a idade elas têm um denominador comum, que é a vaidade"...

[...] "se você não tem dinheiro, mas você é bonito, aí as pessoas vão ficar com você porque você é um coroa bonito, enxuto"...

Essa visão estética, vaidosa e financeira, associada ao processo de envelhecimento, permeia os conflitos vividos por todos aqueles que envelhecem. A autoimagem do idoso se diferencia da realidade apresentada pelas mudanças biofisiológicas. As rugas, a flacidez, os cabelos brancos estão constantemente sendo combatidos pelos idosos, na busca por uma aparência jovem e bela, e o medo de se ter uma aparência envelhecida está sendo explorada pelo mercado farmacêutico e estético. De certa forma, no grupo de idosos homossexuais, essa realidade se mostra pior, visto que a homossexualidade está plenamente ligada à vaidade, característica desse grupo afirmada por Gabriel.

Associado a essa questão, observa-se o aspecto financeiro, na medida em que o idoso normalmente perde sua independência financeira, e seus filhos, acompanhantes e a sociedade julgam que existe uma relação direta entre envelhecimento, falta de autonomia e dependência. Desse modo, a família e a sociedade assumem as questões financeiras e excluem o idoso. Isso talvez aproxime a ideia do velho feio, mal cuidado e dificulte as relações.

Porém, o envelhecimento não é igual para todos, existe um outro lado, talvez em menor número de idosos, que detém independência pessoal e financeira, permitindo assim um enveIhecimento com qualidade, autonomia, eficácia, auxiliando no processo de decisões pessoais, na condução da sua própria vida, das suas vontades e relacionamentos.

Goldstein e Siqueira (2000), em estudo realizado, observaram que no Brasil o gênero, a etnia e a classe social são determinantes para a qualidade de vida da pessoa idosa e identificaram que mesmo no contexto de desigualdade social existente no Brasil alguns idosos conseguem viver a velhice de modo diferente, mais rico e inovador, quando comparado aos idosos de antigamente. 


\section{temporalis}

Seu estilo de vida é muito próximo dos idosos que vivem nos países desenvolvidos, porém essa é uma realidade que difere quanto ao poder aquisitivo, pois a pobreza ainda limita as oportunidades e agrava as dificuldades físicas e sociais da velhice.

A nossa sociedade é capitalista e deixa uma marca de poder para aquele que possui uma boa condição social, de modo que muitas relações se constituem dessa maneira. É possível que um dos mitos que permeiam a homossexualidade e a velhice esteja embasado na relação de "consumo", assim, pessoas idosas com boas condições financeiras, que não precisam dar muitas explicações ou satisfações para a sociedade, assumem suas relações com mais facilidade. Em sua fala, Gabriel evidencia esse aspecto de forma bastante clara, apontando que existe uma relação direta entre homossexualidade, envelhecimento, aparência e dinheiro.

Cabe perguntarmos se essas questões também seriam consideradas como medos daqueles homossexuais que envelhecem, pois observam um corpo não tão viril e a necessidade de manter uma boa condição financeira, a fim de sustentar suas relações. Gabriel, em seu discurso, desqualifica uma relação "prostituta", porém interliga diretamente essas questões.

Pressionados entre as múltiplas exigências adaptativas que as alterações do envelhecimento comportam, os indivíduos enfrentam entraves para garantir a identidade pessoal e a integridade de alguns papéis e funções, principalmente aqueles relacionados à sexualidade, que a sociedade atentamente vigia e sanciona (VASCONCELLOS et al., 2004, p. 413).

Considerando os preconceitos e a ignorância dirigida à sexualidade do idoso, Arcoverde (2006) descreve que a sexualidade é uma característica humana que não se perde com o tempo, mas vai se redesenhando, conforme a história de vida do indivíduo em sua trajetória existencial. Elucida ainda que o que deve ser compreendido e modificado em nossa cultura em relação ao idoso e sua sexualidade é o mito sustentado de que ela diminui automaticamente com o avançar da idade até chegar a uma velhice assexuada. 
Talvez isso ocorra, tendo em vista que encarar o processo de envelhecimento permite reconstruções e até mesmo uma libertação quanto a sua sexualidade, bem como seu desejo sexual, após o cumprimento dos deveres sociais impostos pela sociedade e pela família.

Dessa forma, impregnada de preconceitos, a sociedade olha tardiamente para a relação envelhecimento-homossexualidade, 0 que torna essa temática ainda incipiente no universo acadêmico, reforçando a importância de se conhecer, em face dos homossexuais, as concepções sobre o envelhecimento e suas estratégias de enfrentamento para lidar com essa fase do ciclo da vida, situando as implicações do ser homossexual, envolvendo uma percepção holística a partir do próprio indivíduo, que se torna alvo de duplo preconceito: a velhice e a homossexualidade (BIER, 2004).

Diante dessa realidade, muitos medos e conflitos fizeram parte do envelhecimento do homossexual, excluído, discriminado, desamparado, "escondido no armário" ou assumido e reprimido. Porém, o que buscamos hoje, com uma nova abordagem, diante de um mundo em constantes mudanças e evoluções, é entender melhor esse velho, acolhê-lo, inseri-lo, permitindo o seu livre direito de ir e vir, como cidadãos de bem e não como criminosos.

Sobretudo, independentemente da orientação sexual, é constante a necessidade de maximizar a satisfação pessoal ao longo do período de envelhecimento, mantendo a autonomia do idoso, enquanto isso for possível. Assim, é preciso garantir o necessário suporte de cuidados, a participação na comunidade, o envelhecer dignamente no local onde guardam suas memórias afetivas, seus pertences, estando próximos a parentes e familiares; desse modo, o envelhecimento passa a ser significativo, porém isso se torna mais difícil para um idoso homossexual (SILVA, 2009). Como podemos visualizar no trecho abaixo, segundo Gabriel, o homossexual que envelhece também tem sonhos, desejos e necessidades:

[...] "vou procurar viajar mais, continuar lendo mais, porque eu acho que vou fazer isso até o fim da vida, porque são duas coisas que eu gosto e isso não vai 


\section{temporalis}

me impedir de frequentar o meio social, de ir a boates, de namorar, encontrar, por exemplo, uma pessoa da minha faixa de idade, claro que não vai ser da mesma forma, dentro das limitações que é de praxe, porém eu vou continuar vivendo com a mesma intensidade, porque os meus valores vão permanecer, os meus valores eu acho que são o essencial, porque eles vão comigo para sempre...".

Gabriel demonstra satisfação diante de suas escolhas, de suas relações e traz consigo algumas constatações quanto ao seu processo de envelhecimento. Baseia-se na valorização das potencialidades e virtudes humanas, contribuindo para sua prosperidade. Além disso, o senso de autoeficácia está presente em sua fala, o qual demonstra um enfoque orientado que Gabriel tem acerca de um envelhecimento bem-sucedido.

Segundo Neri e Freire (2000), a autoeficácia é um importante mediador das percepções e dos comportamentos de pessoas de todas as idades com relação à saúde física, à funcionalidade física, intelectual e social, ao manejo de recursos físicos e sociais do ambiente em que vivem e ao manejo de cognições, sentimentos, emoções, motivações e metas.

Diante da sua perspectiva de vida, dos seus desejos e sonhos, Gabriel demonstrou que a homossexualidade, a sua aceitação e reconhecimento, associados a uma boa condição financeira e social, funcionam como um impulso na tomada de decisões, elementos que se tornaram fundamentais à sua personalidade, influenciando em suas escolhas, em suas crenças pessoais, exercendo influência direta sobre o próprio nível de funcionamento e sobre os eventos que permeiam a sua vida.

Neri e Freitas (2000) apontam que o envelhecimento bem-sucedido é definido por três critérios: baixa probabilidade de incapacidade relacionada à doença, alta capacidade física e cognitiva e envolvimento ativo com a vida.

Assim, observamos que o estilo de vida de Gabriel influenciará diretamente na sua velhice e até mesmo em como ele vai envelhecer e lidar com essa etapa. 
Porém essa é a realidade de Gabriel, será que podemos estendê-la a dos nossos idosos de hoje? O idoso homossexual, como aponta Silva (2009), tem sido excluído de políticas, de serviços (públicos ou privados) e da proteção em lei. Suas necessidades são desconhecidas e ocupam uma incômoda posição não apenas frente ao modelo de "sexualidade desejável" (heterossexual), como também diante do modelo de "homossexualidade" desejável (jovem) e do modelo de atenção à saúde (centrados em entidades familiares, as quais, legalmente, homossexuais não podem formar laços colaterais ou de descendência).

Na sociedade heterossexual, o medo da velhice está pautado em diferentes aspectos, desde o começo do fim da beleza física até a solidão. Para os homossexuais, esses medos talvez se acentuam pela vivência baseada num modelo diferenciado, no qual os arranjos sociais, familiares e afetivos se circunscrevem de maneira distinta (POCAHY, 2008).

Lima (2005) enfatiza que é inevitável na velhice e no enveIhecimento não imaginar que o corpo envelhece, associado aos demais aspectos que se agregam à velhice. Dessa forma, há a necessidade de adaptar-se à deterioração da saúde, às perdas, à discriminação pela idade e ao medo de morrer, para, assim, evitar a interrupção do significado do ser integral ao indivíduo que envelhece.

Se olhar no espelho nessa fase deve ser algo não tão fácil, revelar as marcas do corpo, bem como o estigma do velho rabugento, talvez expresse o temor de envelhecer.

"[...] seria o rosto mesmo que eu tenho, um pouco mais papado, às vezes eu acho que eu seria um pouco rabugento, porque eu sou muito exigente e a idade faz com que a gente seja um pouco mais rabugento..."

"[...] mas não seria ranzinza no sentido de maltratar as pessoas, eu sempre fui muito generoso, mas eu sempre aprendi muito, e muito uma coisa: a valorizar as pessoas que me valorizam, eu valorizava muito as pessoas que na minha frente eram uma coisa e por trás "sentavam o pau" em mim principalmente por essa opção, depois isso me decepcionava, que 


\section{temporalis}

parecia que eu estava comprando alguma coisa, hoje em dia eu não compro, eu conquisto, e na veIhice vai ser a mesma coisa...".

Os aspectos biofisiológicos, associados a questões psicossociais, para os homossexuais são elementos marcantes no processo de envelhecimento. Desse modo, seus medos e conflitos são construídos talvez como uma resposta a condições impostas por uma sociedade antiga e pouco esclarecida sobre elementos que constituem o envelhecer.

\section{CONCLUSÃO}

Silva (2009, p. 40) confirma que a atual omissão legislativa e a timidez acadêmica acerca dos direitos homossexuais apontam para a incompatibilidade não apenas com o ideal dos direitos humanos, mas também com os propósitos propugnados pelo Estatuto do Idoso e, especificamente, com o compromisso político figurado no Programa de Ação "Brasil sem Homofobia”, cujos princípios abrangem a inclusão da perspectiva da não discriminação por desejo sexual e promoção dos direitos humanos de "gays, lésbicas, transgênicos e bissexuais" nas políticas públicas e estratégias do Governo Federal.

Idosos homossexuais existem e, apesar de suas diferenças, enfrentam as mesmas dificuldades, medos e conflitos que seus pares etários heterossexuais. Sendo assim, para um envelhecimento bem-sucedido, devem ser garantidos a todos os cidadãos, sem quaisquer tipos de distinção, habitação, sistema de saúde, educação continuada, transporte, luta contra a discriminação e serviços adequados. No entanto, para que isso aconteça, devemos estudar, pesquisar, entender e desvendar os medos e os conflitos que cercam a homossexualidade na senescência, tendo sido essa perspectiva o intuito desta pesquisa.

Uma proporção desconhecida de idosos solteiros é homossexual - tanto homens quanto mulheres. Esta população é totalmente negligenciada pela pesquisa. Sinaliza-se, logo a princípio, que sistematicamente os direitos dos homossexuais, sobretudo homossexuais idosos, são ignorados mesmo nos altiplanos da academia, excluindo-os, intencionalmente ou não, da participação no processo 
científico e da fruição dos benefícios que este poderá lhes trazer, uma garantia de direitos humanos expressa na Declaração dos Direitos do Homem, artigo XXVII (CALDAS, 2006, p. 330).

O envelhecer de Gabriel não deve ser diferente do de Marias e Joãos. Gênero e sexo não devem ser descritores que estabeleçam uma melhor ou pior velhice, pois os direitos devem ser os mesmos, o entendimento e a compreensão também, bem como o respeito que todo ser humano merece, independentemente de seu desejo sexual.

\section{REFERÊNCIAS}

ARCOVERDE, M. A. A percepção da sexualidade do corpo do idoso. 2006. 88f. Dissertação de (Mestrado em Enfermagem) - Programa de pós-graduação em Enfermagem, Universidade Federal do Paraná, Curitiba, 2006.

AURÉLIO. Dicionário de Língua Portuguesa. Disponível em: <http://www.dicionariodo aurelio.com/>. Acesso em: 10 jan. 2014.

BARDIN, L. Análise de Conteúdo. Tradução de Luís Antero Reto e Augusto Pinheiro. São Paulo: Edições 70, 2011.

BIER, A. L. S. Sobre cinemas e videolocadoras pornôs, províncias de outros corpos e outros significados. 2004. Dissertação (Mestrado em Antropologia Social) - Universidade Federal do Rio Grande do Sul, Porto Alegre, 2004.

CALDAS, C. P. Cuidado familiar. In: VERAS, R.; LOURENÇO, R. Formação humana em Geriatria e Gerontologia: uma perspectiva interdisciplinar. Rio de Janeiro: UNATI/UERJ, 2006. p. 335-349.

CAMARANO, A. A. Envelhecimento da população brasileira: uma construção demográfica. In: FREITAS, Elizabete Viana et al. Tratado de Gerontologia e Geriatria. Rio de Janeiro: Guanabara Koogan, 2006. p. 88-104.

CARVALHO, J.A. M; GARCIA, R. A. The aging process in the Brazilian population: a demographic approach. Cad. Saúde Pública, v. 19, n. 3, p. 725-733, jun. 2003. Disponível em: <http://www.scielo.br/ 


\section{temporalis}

scielo.php?pid=S0102-311X2003000300005\&script=sci_arttext $>$. Acesso em: 05 jan. 2014.

GALVÃO, A; CÂMARA, J. Instruções para a pesquisa "Conceito de currículo e educação". Apostila, não publicada, Mestrado em Educação. Brasília: UCB, 2011.

GOLDSTEIN, L.; SIQUEIRA, M. E. C. Heterogeneidade e diversidade nas experiências de velhice. In: NERI, A. L.; FREIRE, S. A. E por falar em boa velhice. São Paulo: Papirus, 2000. p. 113-124.

HULLEY, S. B. et al. Delineando a pesquisa clínica: uma abordagem epidemiológica. Porto Alegre: Artmed, 2008.

LIMA, T. G. Tornar-se velho: olhar da mulher homossexual. 2005. Dissertação (Mestrado em Gerontologia) - Pontifícia Universidade Católica de São Paulo, São Paulo, 2005.

MARAVILHA, L. M. M. Representando envelhecimentos nos percursos da hetero e da homossexualidade masculina. 2010. Dissertação (Mestrado em Psicologia) - Universidade Federal de Pernambuco, Recife, 2010.

NERI, A. L.; FREIRE, S. A. E por falar em boa velhice. São Paulo: Papirus, 2000.

NUNAM, A. Homossexualidade: do preconceito aos padrões de consumo. Rio de Janeiro: Caravansarai, 2003.

OLIVEIRA, M. L. C.; OLIVEIRA, S. R. N.; IGUMA, L.T. O processo de viver nos filmes: Velhice, sexualidade e memória em Copacabana. Texto contexto Enfermagem, Florianópolis, v. 16, n. 1, p. 157-62, jan./mar. 2007.

PINHO, O. @s outr@s cariocas: homoerotismo, hegemonia e história. Cadernos Pagu, [S.1.], v. 31, p. 547-552, jul./dez. 2008.

POCAHY, F. Marcas do poder: o corpo (do) velho-homossexual nas tramas da hetero e homonormatividade. Fazendo gênero 8 Corpo, Violência e Poder, Florianópolis, v. 8, ago. 2008. 
RISMAN, A. A sexualidade e a terceira idade: uma visão histórico-cultural. Textos Envelhecimento, Rio de Janeiro, v. 8, n. 1, 2005.

SANTOS, J. O. A Formação do profissional fisioterapeuta na perspectiva de docentes e discentes. 2002. 153p. Dissertação (Mestrado em Educação) - UCB, Brasília, 2002.

SERAPIONI, M. Métodos Qualitativos e Quantitativos na pesquisa social em saúde: algumas estratégias para a integração. Ciência e Saúde Coletiva, Rio de Janeiro, v. 5, n. 1, jan./mar. 2000.

SILVA, A. C. A. O pote de ouro ao fim do arco-íris: o reconhecimento da cidadania de idosas e idosos homossexuais. 2009. Dissertação (Mestrado em Direito) - Instituto Ciências Jurídicas, Programa de Pós-graduação em Direito, Universidade Federal do Pará, Belém, 2009.

VASCONCELLOS, D. et al. A sexualidade no processo de envelhecimento: novas perspectivas - comparação transcultural. Estudos de Psicologia, v. 9, n. 3, p. 413-419, 2004. 